\title{
The Dicyano Compound Induces Autophagic or Apoptotic Cell Death Via Twist/C-Myc Axis Depending on Metastatic Characteristics of Breast Cancer Cells
}

\section{Ozge ALVUR}

Van Yuzuncu Yil University: Van Yuzuncu Yil Universitesi

\section{Hakan KUCUKSAYAN}

Pamukkale University: Pamukkale Universitesi

\section{Yasemin BAYGU}

Pamukkale Üniversitesi: Pamukkale Universitesi

\section{Nilgun KABAY}

Pamukkale Üniversitesi: Pamukkale Universitesi

\section{Yasar GOK}

Usak University: Usak Universitesi

Hakan AKCA ( $\nabla$ hakca@pau.edu.tr)

Pamukkale Üniversitesi: Pamukkale Universitesi

\section{Research Article}

Keywords: Autophagy, Apoptosis, EMT, c-Myc, Twist

Posted Date: June 24th, 2021

DOI: https://doi.org/10.21203/rs.3.rs-590805/v1

License: (c) (i) This work is licensed under a Creative Commons Attribution 4.0 International License.

Read Full License

Version of Record: A version of this preprint was published at Molecular Biology Reports on November 13th, 2021. See the published version at https://doi.org/10.1007/s11033-021-06817-9. 


\section{Abstract}

Breast cancer is a heterogeneous disease which has distinct subtypes and therefore development of novel targeting treatments to fight aganist breast cancer is needed. Although autophagy and apoptosis considered as the major programmed cell death mechanisms are among the current target mechanisms, there are some difficulties in clinical treatment such as the development of drug resistance and cancer recurrence. Therefore it is important that illumination of distinctive mechanisms between cancer types for development novel treatment strategies. In this study, we examined the anti-proliferative effects of the triazole linked galactose substituted dicyano compound (hereafter referred to as the dicyano compound (the DC)) on two different breast cancer cell lines, MDA-MB-231 and MCF-7. We determined that response of each cell lines to the DC was different, since autophagy was induced in MDA-MB-231 and apoptosis was induced in MCF-7. For this reason, we hypothesized that these different responses may be due to the different characteristics of the cells and evaluated effects of aggresiveness degrees of both cell lines on response to the DC. As a result of our analysis, we determined that c-Myc regulation in both cell lines was different upon the DC treatment depending on expression of Twist, an epithelial-to-mesenchymal transition (EMT) mediator. Therefore, we suggest that Twist/c-Myc axis may have a role in different response to the $\mathrm{DC}$-induced cell death pathways in breast cancer subtypes.

\section{Introduction}

Breast cancer is the second most common cancer type which is diagnosed approximately in one in eight women during their lifetime and is reason of 571.000 of 8.8 million cancer-related deaths (World Health Organization, 2015). Although breast cancer is the one of the most sensitive solid tumors to chemotherapy, drug resistance and tumor recurrence can develop in some of patients with breast cancer. Recurrence of breast cancer gives more metastatic characteristic to the cancer cells and promotes drug resistance. Unfortunately, drug resistance development is among the major problems in breast cancer fighting [1,2]. Also, all of breast cancer types cannot be treated same approach. For example, triplenegative breast cancer (TNBC) does not express estrogen and progesterone receptors and lacks human epidermal growth factor receptor 2 (HER2) overexpression or amplification. Therefore, hormonal therapies or treatments with related antibodies are ineffective for patients with TNBC [2,3]. In this context, development of novel anti-cancer agents, contributing to cancer treatment by targeting cellular mechanisms in cancer cells has a critical importance.

Various cellular events such as disfunctions of programmed cell death mechanisms and EMT contribute metastasis and recurrence of cancer [4,5]. While initial phase of metastasis progresses more rapidly, the percentage of cells that can pass to colonization stage, which is the last stage of metastasis, is only about $0.01 \%$. As the reason of that invasive cell number decrease, it is considered as activations of programmed cell death mechanisms including autophagy and anoikis [6,7]. Autophagy is a process which is induced under stress conditions such as starvation and aims to maintain cell survival as long as possible. In this process, cytoplasmic content which includes organelles and proteins is degraded in lysosomal pathway. Recent studies have revealed that autophagy may function as a survival or a cell 
death mechanism depending on type and stage of cancer. It is important to elucidate the details of this mechanism for autophagy-targeted cancer treatment [8]. Autophagy promotes cell growth and survival especially in solid tumor cells, since it performs energy and protein transduction. Therefore, blocking of autophagy may be a proper strategy for treatment of such tumors [9]. In contrast, it has been shown that autophagy depending on several and variable factors (cell type, signal type and duration, etc) could also cause tumor suppression, followed by the induction of apoptosis (Liang et al., 1999). Since autophagy could leads to tumor growth and tumor regression dependent on several and variable factors (cell type, signal type and duration, etc), all aspects of autophagy-induced cell death regared as a favorable strategy for chemotherapy should be further explained.

There are a number of studies showing that autophagy is related with apoptosis pathways [8,10-12]. Expression changes and mutual interactions of proteins associated with both autophagy and apoptosis pathways play crucial role to decide the cell fate concluding survival or cell death. The balance between apoptosis and autophagy can conclude in a different way. Autophagy may deplete inhibitors of apoptosis, so it can promote apoptosis $[13,14]$. Also, autophagy can play similar role with apoptosis for cell death by recruiting same signals. Alternatively, autophagy decreases cellular stress and delays initiation of apoptotic cell death. Moreover, apoptosis leads to cleavage of key proteins of autophagy (Atg proteins) and thus it can reduce autophagy and then fragments of these proteins can induce apoptosis [15-19]. Autophagy may provide elimination of cancer cells and it can be prefered when apoptotic pathway is blocked [20]. Autophagy can increase the effectiveness of cancer treatment either alone or in combination with other cell death pathways [21]. Several anti-cancer drugs that cause DNA damage and inhibit the polymerization of microtubule may also affect autophagy. However, the mechanism of action of these drugs on autophagy is not clearly known [22]. Although some studies have concluded opposite results, a number of studies suggest that inhibition of autophagy with cancer therapeutics reduces tumor cell death and promotes tumor growth [22-24]. The discovery of novel chemical agents targeting autophagy mechanism may be an alternative approach to development of anticancer-effective drugs.

Cancer cells could display variable characteristics depending on the origin and stage of the tumor (Blankenberg, 2009; Hoelder et al., 2012; Li et al., 2017). As is known, one of the main difference between cancer cells and normal cells is their energy metabolisms. Because cancer cells convertes the high amount of glucose to lactate even in the presence of oxygen (called as Warburg effect or aerobic glycolysis) (Liberti and Locasale, 2016). The novel chemical compound used in this study was synthesized by the scientists at The Department of Chemistry, Pamukkale University and its molecular structure was designed as compound (2,3-bis[1-(2,2,7,7-tetramethyltetra-hydro-bis[1,3]dioxolo[4,5-b;4',5'd]pyran-5,methyl)-1H-[1,2,3]triazol-4-yl methylsulfanyl]-but 2-enedinitrile) to attach a sugar molecule at position of 6 [31]. Thus, cancer cells can recognize and metabolize this compound more and better than normal cells. In this study, we aimed to investigate the potential effects of the DC on programmed cell death mechanisms, especially autophagy in MDA-MB-231 and MCF-7 breast cancer cells, exhibiting metastatic and non-metastatic characteristics, respectively and found that Twist/c-Myc axis could be a decisive factor autophagy-induced apoptosis or autophagic cell death depending on metastatic 
capacities of the breast cancer cells. Thus, our results indicates that the DC may have a potential as a therapeutic agent for breast cancer.

\section{Materials And Methods}

\subsection{Cell Lines and Culture Conditions}

MDA-MB-231 and MCF-7 breast cancer cell lines were obtained from the American Type Culture Collection (ATCC, Manassas, VA, USA). MDA-MB-231 and MCF-7 cells were cultured in RPMI 1640 and DMEM culture medium, respectively, with $10 \%$ fetal bovine serum, $100 \mathrm{mg} / \mathrm{mL}$ penicillin, $50 \mathrm{mg} / \mathrm{mL}$ streptomycin and $1 \mathrm{mM}$ glutamine at $37^{\circ} \mathrm{C}$ in $5 \% \mathrm{CO}_{2}$.

\subsection{Chemicals}

\subsubsection{Synthesis of 2,3-bis[1-(2,2,7,7-tetramethyl-tetrahydro- bis[1,3]dioxolo[4,5-b;4',5'-d]pyran-5,methyl)-1H-[1,2,3]triazol- 4-ylmethylsulfanyl]-but-2-enedinitrile (the triazole linked galactose substituted dicyano compound (DC))}

Preparation of the DC was explained in detail in our previous studies [31,32]. Molecular structure of the DC is shown in Fig. 1.

\subsubsection{The activation and the inhibition of autophagy}

We used chloroquine for blocking autophagy in the last stage of process. Chloroquine, the classic inhibitor of autophagy, accumulates in acidic lysosomes and increases lysosomal pH and hence inhibits lysosomal hydrolases and prevents autophagosomal fusion and degradation. In this study, we used 35 $\mu \mathrm{M}$ chloroquine for only MDA-MB-231 cell line during 24 hours in medium according to manufecturer's instructions (CST \#14774). Torin1 is an effective inducer of autophagy and in this study, we used 100nM Torin 1 for only MCF-7 cell line during 24 hours in medium according to manufecturer's instructions (CST \#14379).

\subsection{Cell Viability Assay by MTT}

MDA-MB-231 and MCF-7 cells were seeded at a density $2.5 \times 10^{3}$ cell/well in 96-well plates and incubated during 24 hours in medium. After that, the cells were treated with the DC at determined concentrations $(5,10,15,20,25 \mu \mathrm{M})$ or dimethyl sulfoxide (DMSO) during 48 hours. Cell viability was measured by using Vybrant ${ }^{\circledR}$ MTT Cell Proliferation Assay Kit according to the manufacturer's instructions (Thermo Fischer Scientific, Waltham, MA, USA). Formazan formation was measured spectrophotometrically at $560 \mathrm{~nm}$ wavelength by Promega Glomax-Multi Microplate Reader.

\subsection{Cell invasion assay}


Invasion capability of the cells was analyzed by a Matrigel invasion chambers with 8-mm membrane pores (BD Biosciences, USA) as previously describe (Kucuksayan and Akca, 2017). Briefly, the cells cultured in serum-free conditions were seeded in upper chamber and the media containing $10 \%$ FBS was added to lower chamber. After that, the DC $(1.46 \mu \mathrm{M})$ was added to both chambers to detect the effect of it on invasion capacity of MDA-MB-231. The cells were allowed to migrate for $22 \mathrm{~h}$ at $37^{\circ} \mathrm{C}$ according to the manufacturer's instructions.

\subsection{Western Blot Assay}

All cell lysates were prepared in ice-cold RIPA lysis solution (CST \#9806). Western blot analysis was performed as previously described [32]. Anti-LC3B (CST \#14774), anti-BAX (CST \#5023), anti-BCL-2 (CST \#15071), anti-p53 (Santa Cruz, sc-55476), anti-p21 (Santa Cruz, sc-397), anti-cMyc (Santa Cruz, sc-40), anti-Twist (Santa Cruz, s-81417) and anti-GAPDH (Cell Signaling Technology \#2118) antibodies were used.

\subsection{Terminal deoxynucleotidyl transferase dUTP nick end labeling (TUNEL) assay}

To assess apoptosis in breast cancer cell lines after treatment with the DC during $48 \mathrm{~h}$, we used The CF® dye TUNEL Assay Apoptosis Detection Kit (Biotium Inc.), according to the manufacturer's instructions and as described previously [32].

\subsection{Transient Transfection}

Expression vectors pcDNA3.1-Twist and pcDNA3.1-Mock (for control) were used in this study. MDA-MB231 and MCF-7 cells were seeded at a density of $2.5 \times 10^{5}$ cell/well in 6 -well plates and were transfected with the plasmid vectors by using Lipofectamine 2000 (Thermo Fischer Scientific, USA) according to the manufacturer's instructions. 24 hours after transfection, the medium was discarded and cells were incubated in the medium with the dicyano compund for an additional 48h. Cell lysate preparation and western blot analysis were performed as described below.

\subsection{Statistical Analysis}

All in vitro studies were performed in triplicate and repeated independently to confirm the results. Statistical results of multiple experiments were shown as means \pm S.D. Student's t-test were performed for data analysis. Significance was determined with p-values of $\leq 0.05$.

\section{Results}

\subsection{The DC has an anti-proliferative effect on MDA-MB-231 and MCF-7 cell lines as dose-dependent manner}

We aimed to determine whether the DC has any effect on proliferation of MDA-MB-231 and MCF-7 cell lines. So, we incubated the both cell lines on determined concentrations of the DC ( 0.1 to $25 \mu \mathrm{M})$ during 
48 hours. As seen in the Fig. 2, the DC had a significant anti-proliferative effect on the both cell lines. IC50 values of the DC were also determined on MDA-MB-231 (IC50 $=1.46 \mu \mathrm{M})$ and MCF-7 $($ IC50 $=7.11 \mu \mathrm{M})$. The results showed that MCF-7 cell line has been more resistant to the DC in comparison with MDA-MB231 cell line. We predicted that non-metastatic characteristic of MCF-7 cell line may cause this resistance when compared with metastatic MDA-MB-231 cell line.

\subsection{The DC induced autophagy depending on metastatic characteristics of breast cancer cells}

In our previous study, we determined that the DC may induce autophagy in non-small cell lung cancer (NSCLC) cell lines [32]. Therefore, we firstly wanted to examine autophagy mechanism of breast cancer cells treated by the $\mathrm{DC}$ in this study.

Protein LC3B has two forms in cells: LC3BI (cytoplasmic (16kDa)) and LC3BII (on outer autophagosomal membrane $(14 \mathrm{kDa})$ ). Expression of LC3BII is correlated with autophagosome formation and is used for determination of autophagy. So, we performed western blot assay for determination of autophagy mechanism in both breast cancer cell lines being treated with the DC in a time-dependent manner $(0,1,2$, 24,48 th hours). We used the DC in IC50 values for both cell lines. In MDA-MB-231 cell line, LC3BII expression was induced about 3-fold after 24-hour treatment by the DC and the induction of LC3BII expression was maintained even during 48-hour treatment (Fig. 3a). Although LC3BII expression was slightly induced in the first 2 hours, it was reduced dramatically after 48-hour treatment by the DC in MCF7 cells (Fig. 3b). The results showed the DC induced autophagy in metastatic MDA-MB-231 cells while not induced in long-term manner in non-metastatic MCF-7 cells, suggesting that the DC-induced autophagy could depend on the metastatic characteristics of breast cancer cells.

\subsection{The DC induced apoptosis only in non-metastatic breast cancer cells while it reduced invasiveness of metastatic one}

As we thought that the DC leads to the induction of autophagy in MDA-MB-231 cells not in MCF-7, we performed flourometric TUNEL assay to determine whether it could induce or not apoptosis in both cell lines being treated with the DC during 48 hours and observed that the DC induced apoptosis in MCF-7, but not in MDA-MB-231. As we thought that the DC may cause induction of autophagy in MDA-MB-231, while it may cause induction of apoptosis in MCF-7, we assessed apoptotic cell death by TUNEL assay in both breast cancer cell lines which were treated with the DC during 48 hours. The results showed that the DC induced apoptosis in MCF-7, but not in MDA-MB-231 (Fig. 4a). To verify TUNEL results, we examined the expression levels of pro-apoptotic BAX and anti-apoptotic BCL-2 in the DC-treated cells by perfoming Western blot assay and determined about 1.5-fold increase in expression level of BAX in MCF-7 cell line while 1.5-fold decrease in MDA-MB-231 cell line (Fig. 4b). Conversely, Bcl-2 was decreased about 1.35fold in MCF-7 cell line while it was increased about 1.7 folds in MDA-MB-231 cell line (Fig. 4c). So, 
alterations in expression levels of BAX and BCL-2 in both cell lines are consistent with TUNEL assay results of each cell lines. The results revealed that the DC may cause two different types of programmed cell death in MDA-MB-231 and MCF-7 cell lines. Autophagic cell death occurs in MDA-MB-231 whereas MCF-7 cells undergo apoptotic cell death upon the DC treatment. Also, we wanted to evaluate effects of the DC on invasiveness of metastatic MDA-MB-231 cells. We treated the cells with IC50 value of the DC during 48 hours and observed reduction of invasiveness of the cells about rate of $\% 50$ as compared to untreated group (Fig. 5).

\subsection{The DC regulates c-Myc and p21 in a p53-independent}

\section{manner}

After we established that non-metastatic breast cancer cells is more sensitive to the DC-induced apoptosis than metastatic one which autopahy is stably induced, we wanted to evaluate expression levels of crucial regulatory proteins (p21, p53 and c-Myc) implicated in cell cycle, DNA repair, apoptosis and survival. Thus, we observed whether there is alterations between expression profiles of these proteins in MDA-MB-231 and MCF-7 cells treated with the DC during 48 hours. Western blot assay revealed that p53 expression levels did not change significantly during 48-hour treatment in both cell lines. p21 expression were induced by 2.76 folds for 24 -hour treatment and by 2 folds for 48 -hour treatment in MCF7 cells. Interestingly, the DC caused 1.52-fold increase of c-Myc expression in MDA-MB-231 cells whereas it dramatically repressed c-Myc expression in MCF-7 cells for 48-hour treatment (Fig. 6). Our results clearly showed that the opposite responses of breast cancer cell lines to the $D C$ is due to $c-M y c$ being regulated by $\mathrm{p} 53$-independent manner.

\subsection{Autophagy is required to maintain the stabilization of c- Myc during the DC treatment}

To identify whether autophagy induction by the DC directly correlates with c-Myc, we induced autophagy with Torin 1 in MCF-7 cells preferring apoptosis instead of autophagy in response to the DC treatment. As consistent with our previous results, c-Myc expression was repressed by 2.56 folds by the DC in MCF-7 cells without Torin1. But, in the group with Torin1, c-Myc expression was repressed only by 1.2 folds by the DC in MCF-7 cell line. So, in autophagy induced conditions the DC-dependent c-Myc repression was lower in MCF-7 cell line (Fig. 7a). Meanwhile, the DC diminished c-Myc expression in MDA-MB-231 cells in presence of chloroquine, a strong inhibitor of autophagy (about 1.4 folds). Whereas, under normal conditions, c-Myc expression was induced by 1.3 folds upon the DC treatment (Fig. 7b). All these results revealed that the transcription factor c-Myc known especially as a cell cycle regulator could also be a marker to determine cell fate during autophagy.

\subsection{Twist decides regulatory role of c-Myc for selection of cell death mechanism}

Because of being a major transcriptional activator of Twist which plays crucial roles in metastasis especially EMT process and also has been shown to have a regulatory effect on autophagy [34-37], we 
hypothesized that it could implicate in the DC-induced c-Myc downregulation in MCF-7 cells exhibiting a epithelial character. As we have confirmed by western blotting, endogenous Twist expression is lower in non-metastatic MCF-7 cell line than in metastatic MDA-MB-231 [38,39] (Fig. 8a). We transfected MCF-7 cells with pcDNA3.1-Twist vector to upregulate Twist and subsequently we verified Twist overexpression (Fig. 8b). Then, we treated the Twist-transfected MCF-7 cell line with the DC for 48 hours and observed that c-Myc was not downregulated upon the DC treatment in MCF-7 cells overexpressing Twist while cMyc expression was decreased in presence of the DC treatment in the negative control MCF-7 cells (Fig. 8c). Consequently, we suggest that Twist/c-Myc axis may regulate the selection of cell death mechanism of breast cancer cells like a switch protein during the DC treatment.

\section{Discussion}

Breast cancer is a highly heterogeneous cancer type which possesses diverse phenotypic and morphologic features. Therefore, treatment strategies may vary for each breast cancer type. For example, hormone therapies are not helpful for Triple-Negative Breast Cancers or using anti-HER2 drugs is not to benefit for Luminal A type breast cancer which is tend be HER2- ${ }^{-}$while this treatment strategy is used for HER2 ${ }^{+}$Luminal B. Also, inappropriate treatment application may cause various side effects or drug resistence development. So, accurate diagnosis and treatment is vital importance for breast cancer treatment such as other cancer types and development of novel therapeutic approaches or anti-cancer agents is needed and important for fighting aganist cancer.

Autophagy plays a survival role for normal cells because of being a mechanism which maintains energy homeostasis and is a source of nutriation and an elimination mechanism of damaged organelles and proteins. However, autophagy plays also important roles in carcinogenesis. In a tumor microenvironment, which contains stress conditions such as hypoxia, oxidative stress and nutrient deprivation, autophagy provides survival conditions by maintaining biomolecules and energy for cancer cells and causes adaptation of cancer cell to tumor microenvironment, therefore autophagy plays role as a tumor promoting oncogenic mechanism $[40,41]$. But, on the other hand, autophagy has a tumor suppressor role because of maintaining genomic stability, elimination of reactive oxygen species (ROS), degradation of oncogenic proteins and induction of immunresponse. Bidirectional role of autophagy in tumorigenesis depend on type and stage of cancer [42]. Thus, relationship between autophagy and cancer still has been controversial. Among the programmed cell death mechanisms, espacially apoptosis has been widely studied in cancer biology. The first studies suggesting that apoptosis blocks tumor progression by elimination of malignant cells were performed in 1970s [43]. The mechanisms which cause dysregulation of apoptosis and promote tumor progression can be summarized as disruption of the balance between pro-apoptotic and anti-apoptotic proteins, distortion of death receptor signals and reduction of caspase function [43]. Cancer cells generally tend to evade from apoptosis and thus, they may gain capability of escape from immun system surveillence. In short, it is known that programmed cell death mechanisms are the first barriers preventing proliferation and survival of cancer cells. Therefore, various cancer treatment strategies targeting programmed cell death mechanisms have been developed and used until 
now. The type of programmed cell death which is induced by anti-cancer agent is depend on multiple factors such as type of cancer cell, dose of drugs, tumor microenvironment and type of cellular damage. So, to understand differences between programmed cell death mechanisms may contribute development of novel anti-cancer agents and treatment approaches.

In our previous study, we investigated cellular effects of the DC on lung cancer cells and revealed that the DC induced autophagic cell death in an apoptosis-independent manner in NSCLC cells [44]. In this study, we aimed to investigate the biological effects of the DC in breast cancer according to metastatic features of cancer cells. We performed our experiments by using two different breast cancer cell lines, MDA-MB231 and MCF-7 because of being cell culture models of different subtypes of breast cancer. MCF-7 cell line is estrogen receptor, progesterone receptor and HER2 positive, while MDA-MB-231 is negative. So, Luminal A breast cancer subtype MCF-7 is more appropriate cell line model for hormone therapy studies while triple-negative breast cancer subtype MDA-MB-231 cell line is generally used for chemotherapy and radiotherapy studies. MCF-7 cell line is a non-metastatic, but MDA-MB-231 is a highly metastatic cell line because of overexpression of EMT markers (Comşa et al., 2015; Subik et al., 2010).

Firstly, we examined the anti-proliferative effects of the DC on both breast cancer cell lines and determined that the DC suppressed proliferation of both cell lines. Depending on our previous study which showed that the DC induced autophagic cell death in NSCLC cell lines, we thought that the DC may induce programmed cell death mechanisms in breast cancer cell lines and we firstly evaluated protein expression levels of LC3BIl for autophagy determination. We observed that autophagy was induced in MDA-MB-231 cell line during 48 hours, but it was only induced for the first hour and then it was reduced gradually during 48 hour-treatment in MCF-7 cell line (Fig. 3). This result showed that the DC induces a non-autophagic cell death mechanism in MCF-7 cell line unlike MDA-MB-231 cells. Depending on this result, we had two question; which cell death mechanism was induced by the DC in MCF-7 cell line and why these two breast cancer cell lines chose different cell death mechanisms? Therefore, we performed TUNEL assay for both the DC-treated cell lines and we obtained more signals in MCF-7 as compared to MDA-MB-231, indicating that MCF-7 underwent apoptosis process (Fig. 4a). To validate these results, we also evaluated protein expression levels of anti-apoptotic BCL-2 and pro-apoptotic BAX. The results which showed that the DC induced apoptosis in MCF-7 but not MDA-MB-231 cell line verified TUNEL assay results (Fig. 4b,c). Also, the DC reduced the invasive capability of metastatic MDA-MB-231 cells (Fig. 5). Upon this results, we wanted to elucidate the mechanisms which cause selection of different cell death pathways of breast cancer cell lines. Therefore, we hypothesized that the different cellular and genetic characteristics between the two cell lines may be responsible for these results. As is known, MCF-7 cell line is p53-mutant while MDA-MB-231 is p53-wild type. Tumor suppressor p53 is a key regulator which play important role in cell cyle arrest, maintaining cellular genomic integrity and controlling cell growth, senescence, differentiation, and apoptosis [47]. p53-mediated growth inhibition depends on induction of an inhibitor of cyclin-dependent kinases p21 and p21 provides a functional link between p53 and cell cycle control $[48,49]$. Therefore, we evaluated protein expression levels of p53, p21 and another cell cycle and cell death regulator c-Myc. The results showed that p53 expression levels had not any significant change, p21 expression was induced relatively in both the DC-treated cell lines. But interestingly, c-Myc 
expression was induced significantly in MDA-MB-231, while it was downregulated in MCF-7 upon the DC treatment (Fig. 6). Next, to determine whether autophagy has a effect on the DC-induced c-Myc inhibition, we treated MCF-7 and MDA-MB-231 with Torin1 and chloroquine, are an inducer and a blocker of autophagy process, respectively. Chloroquine is a widely used autophagy inhibitor in the last stage of process by increasing lysosomal $\mathrm{pH}$ and blocking lysosome-autophagosome fusion [50]. Torin1 prevents phosphorylation of downstream targets of MTORC1 and so induces autophagy [51]. When we treated MDA-MB-231 cell line with the DC under autophagy-blocked conditions by chloroquine, we observed that C-Myc expression was downregulated significantly whereas c-Myc expression was upregulated upon only the DC treatment under normal conditions (Fig. 7b). Also, we induced autophagy with Torin 1 in MCF-7 cell line and under autophagy-induced conditions the DC treatment could not repress c-Myc expression (Fig. 7a). According to these results, the DC downregulates c-Myc following induction of apoptosis in MCF-7 cells while it upregulates c-Myc following induction of autophagy in MDA-MB-231 cells. However, this is a recoverable mechanism via regulation of autophagy in both cell lines and we thought that there is a mutual interaction between autophagy and c-Myc. Because, MCF-7 has low expression level of c-Myc as compared to MDA-MB-231 [52,53]. In many studies, it was reported the interaction between autophagy and c-Myc (Z. Chen et al., 2019; Toh et al., 2013). Also, it was showed that Apigenin combined wih Gefitinib blocks autophagy by inducing apoptosis through inhibition of c-Myc [56]. Recent studies showed that c-Myc overexpression promotes EMT by downregulating E-cadherin expression in breast cancer (Cho et al., 2010; Gao et al., 2019). EMT is a process that cells lose their epithelial phenotype and acquire mesenchymal features and it was reported that there is a crosstalk between autophagy and EMT in various cancer types in recent studies (H. T. Chen et al., 2019; Gugnoni et al., 2016). As previously mentioned, MCF-7 is a non-metastatic cell line and has a epithelial character while MDA-MB-231 has mesencymal phentype and highly metastatic capacity. Depending on this difference, we thought that metastatic features and expression levels of EMT markers of cell lines may determine the response to the $D C$, hence the cell death mechanism type. Therefore, we performed plasmid transfection for overexpression of Twist in MCF-7 cell line. Because low endogenous Twist expression is observed in MCF-7 as compared to MDA-MB-231 cell line and Twist upregulation may cause induction of EMT, invasion and migration of breast cancer cells [65]. As a result of our analysis, we observed overexpression of c-Myc in exogenous Twist expressing MCF-7 cells treated the DC similar to MDA-MB231 cell line (Fig. 8).

In recent studies, it was reported that cancer cells may induce autophagic cell death mechanism as a response to anti-cancer agents [66-68]. But, it is still unclear that clinic effects of autophagy on cancer. Therefore, as target mechanisms, selection of the distinctive mechanisms between normal cells and cancer cells is may be an useful approach for development of anti-cancer drugs. In this study, we determined that the DC induces autophagic cell death in metastatic breast cancer but it induces apoptotic cell death non-metastatic breast cancer. This different death pathway selections of different cancer cell lines may occur Twist/c-Myc axis, depending on metastatic features of breast cancer cells.

In conclusion, taken together with our previous study, the DC has anti-proliferative effects on lung and breast cancer and causes cell death. But determination of cell death mechanism type is depend on 
cancer cell type, even sub-type. Therefore, further studies is needed to illumination of detailed mechanisms of cellular effects of the DC and distinctive mechanisms between several cancer types. We hope that our findings may provide a novel perspective for interactions of autophagy, apoptosis and EMT pathways and may contribute to further analysis for development of novel anti-cancer therapies.

\section{Abbreviations}

DC: the triazole linked galactose substituted dicyano compound

LC3B: Light chain 3 B

GAPDH: Glyceraldehyde 3-phosphate dehydrogenase

TUNEL: Terminal deoxynucleotidyl transferase dUTP nick end labeling

MTT: Methylthiazolyldiphenyl-tetrazolium bromide

BAX: Bcl-2 Associated X Protein

BCL-2: B-cell lymphoma 2

DC: The dicyano compound (the triazole linked galactose substituted dicyano compound)

\section{Declarations}

\section{Acknowledgements}

The authors are grateful to Dr. Osman Nidai OZES because of his gift pcDNA3.1-Twist and pcDNA3.1Mock.

Funding Info: This study was supported by Pamukkale University Research Foundation (Grant Number: 2018SABE024).

Authors' contributions: All authors contributed to the study conception and design. Material preparation, data collection and analysis were performed by Ozge ALVUR, Hakan KUCUKSAYAN, Yasemin BAYGU, Nilgun KABAY, Yasar GOK and Hakan AKCA. The first draft of the manuscript was written by Ozge ALVUR and all authors commented on previous versions of the manuscript. All authors read and approved the final manuscript.

Data availability: The datasets used and/or analyzed during the current study are available from the corresponding author on reasonable request.

Consent to participate: Not applicable.

Consent for publication: The authors hereby consent to publication of this study. 


\section{Compliance with Ethical Standards}

Conflicts of interest/Competing interests: The authors declare that they have no known competing financial interests or personal relationships that could have appeared to influence the work reported in this paper.

Research involving Human Participants and/or Animals: This article does not contain any studies with human or animal subjects.

Ethical approval: Not applicable.

Informed consent: Not applicable.

\section{References}

1. Y. Zhou, E.B. Rucker lii, B.P. Zhou, Autophagy regulation in the development and treatment of breast cancer, (2015). https://doi.org/10.1093/abbs/gmv119.

2. L. Carey, E. Winer, G. Viale, D. Cameron, L. Gianni, Triple-negative breast cancer: disease entity or title of convenience?, Nat. Rev. Clin. Oncol. 7 (2010) 683-692. https://doi.org/10.1038/nrclinonc.2010.154.

3. H. Yao, G. He, S. Yan, C. Chen, L. Song, T.J. Rosol, X. Deng, Triple-negative breast cancer: is there a treatment on the horizon?, Oncotarget. 8 (2017) 1913-1924. https://doi.org/10.18632/oncotarget.12284.

4. J. Shi, J. Cao, B.P. Zhou, Twist-BRD4 complex: potential drug target for basal-like breast cancer., Curr. Pharm. Des. 21 (2015) 1256-61. http://www.ncbi.nIm.nih.gov/pubmed/25506891 (accessed July 22, 2019).

5. Y. Wang, B.P. Zhou, Epithelial-mesenchymal Transition-A Hallmark of Breast Cancer Metastasis., Cancer Hallm. 1 (2013) 38-49. https://doi.org/10.1166/ch.2013.1004.

6. I.J. Fidler, Metastasis: quantitative analysis of distribution and fate of tumor emboli labeled with 125 I-5-iodo-2'-deoxyuridine., J. Natl. Cancer Inst. 45 (1970) 773-82.

http://www.ncbi.nlm.nih.gov/pubmed/5513503 (accessed July 23, 2019).

7. Y. Zhou, E.B. Rucker lii, B.P. Zhou, Autophagy regulation in the development and treatment of breast cancer, (2015). https://doi.org/10.1093/abbs/gmv119.

8. D. Denton, T. Xu, S. Kumar, Autophagy as a pro-death pathway, Immunol. Cell Biol. 93 (2015) 35-42. https://doi.org/10.1038/icb.2014.85.

9. A.M.K. Choi, S.W. Ryter, B. Levine, Autophagy in Human Health and Disease, N. Engl. J. Med. 368 (2013) 651-662. https://doi.org/10.1056/NEJMra1205406.

10. S. Mukhopadhyay, $\cdot$ Prashanta, K. Panda, N. Sinha, $\cdot$ Durgesh, N. Das, $\cdot$ Sujit, K. Bhutia, Autophagy and apoptosis: where do they meet?, (n.d.). https://doi.org/10.1007/s10495-014-0967-2. 
11. S. Pattingre, A. Tassa, X. Qu, R. Garuti, X.H. Liang, N. Mizushima, M. Packer, M.D. Schneider, B. Levine, Bcl-2 Antiapoptotic Proteins Inhibit Beclin 1-Dependent Autophagy, Cell. 122 (2005) 927-939. https://doi.org/10.1016/j.cell.2005.07.002.

12. F. Strappazzon, M. Vietri-Rudan, S. Campello, F. Nazio, F. Florenzano, G.M. Fimia, M. Piacentini, B. Levine, F. Cecconi, Mitochondrial BCL-2 inhibits AMBRA1-induced autophagy, EMBO J. 30 (2011) 1195-1208. https://doi.org/10.1038/emboj.2011.49.

13. I.P. Nezis, B. V Shravage, A.P. Sagona, T. Lamark, G. Bjørkøy, T. Johansen, T.E. Rusten, A. Brech, E.H. Baehrecke, H. Stenmark, Autophagic degradation of dBruce controls DNA fragmentation in nurse cells during late Drosophila melanogaster oogenesis., J. Cell Biol. 190 (2010) 523-31. https://doi.org/10.1083/jcb.201002035.

14. J.M.I. Barth, J. Szabad, E. Hafen, K. Köhler, Autophagy in Drosophila ovaries is induced by starvation and is required for oogenesis, Cell Death Differ. 18 (2011) 915-924. https://doi.org/10.1038/cdd.2010.157.

15. E. Wirawan, L. Vande Walle, K. Kersse, S. Cornelis, S. Claerhout, I. Vanoverberghe, R. Roelandt, R. De Rycke, J. Verspurten, W. Declercq, P. Agostinis, T. Vanden Berghe, S. Lippens, P. Vandenabeele, Caspase-mediated cleavage of Beclin-1 inactivates Beclin-1-induced autophagy and enhances apoptosis by promoting the release of proapoptotic factors from mitochondria, Cell Death Dis. 1 (2010) e18-e18. https://doi.org/10.1038/cddis.2009.16.

16. O. Oral, D. Oz-Arslan, Z. Itah, A. Naghavi, R. Deveci, S. Karacali, D. Gozuacik, Cleavage of Atg3 protein by caspase-8 regulates autophagy during receptor-activated cell death, Apoptosis. 17 (2012) 810820. https://doi.org/10.1007/s10495-012-0735-0.

17. V.M.S. Betin, J.D. Lane, Caspase cleavage of Atg4D stimulates GABARAP-L1 processing and triggers mitochondrial targeting and apoptosis, J. Cell Sci. 122 (2009) 2554-2566. https://doi.org/10.1242/jcs.046250.

18. R.T. Marquez, L. Xu, Bcl-2:Beclin 1 complex: multiple, mechanisms regulating autophagy/apoptosis toggle switch., Am. J. Cancer Res. 2 (2012) 214-21. http://www.ncbi.nlm.nih.gov/pubmed/22485198 (accessed June 12, 2018).

19. S. Luo, D.C. Rubinsztein, Apoptosis blocks Beclin 1-dependent autophagosome synthesis: an effect rescued by Bcl-xL, Cell Death Differ. 17 (2010) 268-277. https://doi.org/10.1038/cdd.2009.121.

20. C. Kitanaka, K. Kato, R. ljiri, K. Sakurada, A. Tomiyama, K. Noguchi, Y. Nagashima, A. Nakagawara, T. Momoi, Y. Toyoda, H. Kigasawa, T. Nishi, M. Shirouzu, S. Yokoyama, Y. Tanaka, Y. Kuchino, Increased Ras expression and caspase-independent neuroblastoma cell death: possible mechanism of spontaneous neuroblastoma regression., J. Natl. Cancer Inst. 94 (2002) 358-68. http://www.ncbi.nlm.nih.gov/pubmed/11880474 (accessed July 23, 2018).

21. J.M. Coates, J.M. Galante, R.J. Bold, Cancer Therapy Beyond Apoptosis: Autophagy and Anoikis as Mechanisms of Cell Death, J. Surg. Res. 164 (2010) 301-308. https://doi.org/10.1016/j.jss.2009.07.011. 
22. A. Thorburn, D.H. Thamm, D.L. Gustafson, Autophagy and Cancer Therapy, Mol. Pharmacol. Mol Pharmacol. 85 (2014) 830-838. https://doi.org/10.1124/mol.114.091850.

23. T. Shingu, K. Fujiwara, O. Bögler, Y. Akiyama, K. Moritake, N. Shinojima, Y. Tamada, T. Yokoyama, S. Kondo, Inhibition of autophagy at a late stage enhances imatinib-induced cytotoxicity in human malignant glioma cells, Int. J. Cancer. 124 (2009) 1060-1071. https://doi.org/10.1002/ijc.24030.

24. T. Miyazawa, K. Miyazawa, S. Moriya, T. Ohtomo, X.-F. Che, M. Naito, M. Itoh, A. Tomoda, Combined treatment with bortezomib plus bafilomycin A1 enhances the cytocidal effect and induces endoplasmic reticulum stress in U266 myeloma cells: Crosstalk among proteasome, autophagylysosome and ER stress, Int. J. Oncol. 38 (2011) 643-54. https://doi.org/10.3892/ijo.2010.882.

25. S. Hoelder, P.A. Clarke, P. Workman, Discovery of small molecule cancer drugs: successes, challenges and opportunities., Mol. Oncol. 6 (2012) 155-76. https://doi.org/10.1016/j.molonc.2012.02.004.

26. Y.-J. Li, Y.-H. Lei, N. Yao, C.-R. Wang, N. Hu, W.-C. Ye, D.-M. Zhang, Z.-S. Chen, Autophagy and multidrug resistance in cancer., Chin. J. Cancer. 36 (2017) 52. https://doi.org/10.1186/s40880-0170219-2.

27. F.G. Blankenberg, Apoptosis imaging: anti-cancer agents in medicinal chemistry., Anticancer. Agents Med. Chem. 9 (2009) 944-51. http://www.ncbi.nlm.nih.gov/pubmed/20225999 (accessed June 18, 2018).

28. S. Mansilla, L. Llovera, J. Portugal, Chemotherapeutic targeting of cell death pathways., Anticancer. Agents Med. Chem. 12 (2012) 226-38. http://www.ncbi.nlm.nih.gov/pubmed/22263795 (accessed June 18, 2018).

29. M. V Liberti, J.W. Locasale, The Warburg Effect: How Does it Benefit Cancer Cells?, Trends Biochem. Sci. 41 (2016) 211-218. https://doi.org/10.1016/j.tibs.2015.12.001.

30. A.M. Otto, Warburg effect(s)-a biographical sketch of Otto Warburg and his impacts on tumor metabolism., Cancer Metab. 4 (2016) 5. https://doi.org/10.1186/s40170-016-0145-9.

31. Y. Baygu, B. Yıldız, N. Kabay, Y. Gök, Novel magnesium and zinc porphyrazines containing galactose moieties: Synthesis via click reaction and characterization, Inorg. Chem. Commun. 71 (2016) 35-40. https://doi.org/10.1016/j.inoche.2016.07.001.

32. O. Alvur, O. Tokgun, Y. Baygu, N. Kabay, Y. Gok, H. Akca, The triazole linked galactose substituted dicyano compound can induce autophagy in NSCLC cell lines, Gene. 712 (2019). https://doi.org/10.1016/j.gene.2019.06.025.

33. H. Kucuksayan, H. Akca, The crosstalk between p38 and Akt signaling pathways orchestrates EMT by regulating SATB2 expression in NSCLC cells, Tumor Biol. 39 (2017). https://doi.org/10.1177/1010428317706212.

34. Y. Wang, R. Liao, X. Chen, X. Ying, G. Chen, M. Li, C. Dong, Twist-mediated PAR1 induction is required for breast cancer progression and metastasis by inhibiting Hippo pathway, Cell Death Dis. 11 (2020). https://doi.org/10.1038/s41419-020-2725-4.

35. M. Bertrand, V. Petit, A. Jain, R. Amsellem, T. Johansen, L. Larue, P. Codogno, I. Beau, SQSTM1/p62 regulates the expression of junctional proteins through epithelialmesenchymal transition factors, Cell 
Cycle. 14 (2015) 364-374. https://doi.org/10.4161/15384101.2014.987619.

36. L. Qiang, Y.Y. He, Autophagy deficiency stabilizes TWIST1 to promote epithelial-mesenchymaltransition, Autophagy. 10 (2014) 1864-1865. https://doi.org/10.4161/auto.32171.

37. L. Qiang, B. Zhao, M. Ming, N. Wang, T.C. He, S. Hwang, A. Thorburn, Y.Y. He, Regulation of cell proliferation and migration by p62 through stabilization of Twist1, Proc. Natl. Acad. Sci. U. S. A. 111 (2014) 9241-9246. https://doi.org/10.1073/pnas.1322913111.

38. R. Tan, L. Wang, J. Song, J. Li, T. He, Expression and significance of Twist, estrogen receptor, and Ecadherin in human breast cancer cells and tissues, J. Cancer Res. Ther. 13 (2017) 707. https://doi.org/10.4103/jcrt.JCRT_1396_16.

39. J. Cao, X. Wang, T. Dai, Y. Wu, M. Zhang, R. Cao, R. Zhang, G. Wang, R. Jiang, B.P. Zhou, J. Shi, T. Kang, Twist promotes tumor metastasis in basal-like breast cancer by transcriptionally upregulating ROR1, Theranostics. 8 (2018) 2739-2751. https://doi.org/10.7150/thno.21477.

40. L. Galluzzi, F. Pietrocola, J.M. Bravo-San Pedro, R.K. Amaravadi, E.H. Baehrecke, F. Cecconi, P. Codogno, J. Debnath, D.A. Gewirtz, V. Karantza, A. Kimmelman, S. Kumar, B. Levine, M.C. Maiuri, S.J. Martin, J. Penninger, M. Piacentini, D.C. Rubinsztein, H. Simon, A. Simonsen, A.M. Thorburn, G. Velasco, K.M. Ryan, G. Kroemer, Autophagy in malignant transformation and cancer progression, EMBO J. 34 (2015) 856-880. https://doi.org/10.15252/embj.201490784.

41. N.M. Kocaturk, Y. Akkoc, C. Kig, O. Bayraktar, D. Gozuacik, O. Kutlu, Autophagy as a molecular target for cancer treatment, Eur. J. Pharm. Sci. 134 (2019) 116-137. https://doi.org/10.1016/j.ejps.2019.04.011.

42. K. Sun, W. Deng, S. Zhang, N. Cai, S. Jiao, J. Song, L. Wei, Paradoxical roles of autophagy in different stages of tumorigenesis: Protector for normal or cancer cells, Cell Biosci. 3 (2013). https://doi.org/10.1186/2045-3701-3-35.

43. J.F.R. Kerr, A.H. Wyllie, A.R. Currie, Apoptosis: A basic biological phenomenon with wide-ranging implications in tissue kinetics, Br. J. Cancer. 26 (1972) 239-257. https://doi.org/10.1038/bjc.1972.33.

44. O. Alvur, O. Tokgun, Y. Baygu, N. Kabay, Y. Gok, H. Akca, The triazole linked galactose substituted dicyano compound can induce autophagy in NSCLC cell lines, Gene. 712 (2019). https://doi.org/10.1016/j.gene.2019.06.025.

45. Ş. Comşa, A.M. Cîmpean, M. Raica, The story of MCF-7 breast cancer cell line: 40 Years of experience in research, Anticancer Res. 35 (2015) 3147-3154.

46. D. Flodrova, L. Toporova, D. Macejova, M. Lastovickova, J. Brtko, J. Bobalova, A comparative study of protein patterns of human estrogen receptor positive (MCF-7) and negative (MDA-MB-231) breast cancer cell lines, Gen. Physiol. Biophys. 35 (2016) 387-392. https://doi.org/10.4149/gpb_2016009.

47. K. Subik, J.F. Lee, L. Baxter, T. Strzepek, D. Costello, P. Crowley, L. Xing, M.C. Hung, T. Bonfiglio, D.G. Hicks, P. Tang, The expression patterns of ER, PR, HER2, CK5/6, EGFR, KI-67 and AR by immunohistochemical analysis in breast cancer cell lines, Breast Cancer Basic Clin. Res. 4 (2010) 35-41. https://doi.org/10.1177/117822341000400004. 
48. L. Raycroft, J.R. Schmidt, K. Yoas, M.M. Hao, G. Lozano, Analysis of p53 mutants for transcriptional activity., Mol. Cell. Biol. 11 (1991) 6067-6074. https://doi.org/10.1128/mcb.11.12.6067.

49. J. Wade Harper, G.R. Adami, N. Wei, K. Keyomarsi, S.J. Elledge, The p21 Cdk-interacting protein Cip1 is a potent inhibitor of G1 cyclin-dependent kinases, Cell. 75 (1993) 805-816. https://doi.org/10.1016/0092-8674(93)90499-G.

50. M. Mauthe, I. Orhon, C. Rocchi, X. Zhou, M. Luhr, K.J. Hijlkema, R.P. Coppes, N. Engedal, M. Mari, F. Reggiori, Chloroquine inhibits autophagic flux by decreasing autophagosome-lysosome fusion, Autophagy. 14 (2018) 1435-1455. https://doi.org/10.1080/15548627.2018.1474314.

51. A.M. Andersson, B. Andersson, C. Lorell, J. Raffetseder, M. Larsson, R. Blomgran, Autophagy induction targeting mTORC1 enhances Mycobacterium tuberculosis replication in HIV co-infected human macrophages, Sci. Rep. 6 (2016). https://doi.org/10.1038/srep28171.

52. J. Barretina, G. Caponigro, N. Stransky, K. Venkatesan, A.A. Margolin, S. Kim, C.J. Wilson, J. Lehár, G. V. Kryukov, D. Sonkin, A. Reddy, M. Liu, L. Murray, M.F. Berger, J.E. Monahan, P. Morais, J. Meltzer, A. Korejwa, J. Jané-Valbuena, F.A. Mapa, J. Thibault, E. Bric-Furlong, P. Raman, A. Shipway, I.H. Engels, J. Cheng, G.K. Yu, J. Yu, P. Aspesi, M. De Silva, K. Jagtap, M.D. Jones, L. Wang, C. Hatton, E. Palescandolo, S. Gupta, S. Mahan, C. Sougnez, R.C. Onofrio, T. Liefeld, L. MacConaill, W. Winckler, M. Reich, N. Li, J.P. Mesirov, S.B. Gabriel, G. Getz, K. Ardlie, V. Chan, V.E. Myer, B.L. Weber, J. Porter, M. Warmuth, P. Finan, J.L. Harris, M. Meyerson, T.R. Golub, M.P. Morrissey, W.R. Sellers, R. Schlegel, L.A. Garraway, The Cancer Cell Line Encyclopedia enables predictive modelling of anticancer drug sensitivity, Nature. 483 (2012) 603-607. https://doi.org/10.1038/nature11003.

53. R.T. Lawrence, E.M. Perez, D. Hernández, C.P. Miller, K.M. Haas, H.Y. Irie, S.-I. Lee, C.A. Blau, J. Villén, The proteomic landscape of triple-negative breast cancer., Cell Rep. 11 (2015) 630-44. https://doi.org/10.1016/j.celrep.2015.03.050.

54. M. Tsuneoka, T. Umata, H. Kimura, Y. Koda, M. Nakajima, K. Kosai, T. Takahashi, Y. Takahashi, A. Yamamoto, c-myc induces autophagy in rat 3Y1 fibroblast cells, Cell Struct. Funct. 28 (2003) 195204. https://doi.org/10.1247/csf.28.195.

55. P.P.C. Toh, S. Luo, F.M. Menzies, T. Raskó, E.E. Wanker, D.C. Rubinsztein, Myc inhibition impairs autophagosome formation, Hum. Mol. Genet. 22 (2013) 5237-5248. https://doi.org/10.1093/hmg/ddt381.

56. Z. Chen, D. Tian, X. Liao, Y. Zhang, J. Xiao, W. Chen, Q. Liu, Y. Chen, D. Li, L. Zhu, S. Cai, Apigenin Combined With Gefitinib Blocks Autophagy Flux and Induces Apoptotic Cell Death Through Inhibition of HIF-1a, c-Myc, p-EGFR, and Glucose Metabolism in EGFR L858R+T790M-Mutated H1975 Cells, Front. Pharmacol. 10 (2019). https://doi.org/10.3389/fphar.2019.00260.

57. L.S. Hart, J.T. Cunningham, T. Datta, S. Dey, F. Tameire, S.L. Lehman, B. Qiu, H. Zhang, G. Cerniglia, M. Bi, Y. Li, Y. Gao, H. Liu, C. Li, A. Maity, A. Thomas-Tikhonenko, A.E. Perl, A. Koong, S.Y. Fuchs, J.A. Diehl, I.G. Mills, D. Ruggero, C. Koumenis, ER stress-mediated autophagy promotes Myc-dependent transformation and tumor growth, J. Clin. Invest. 122 (2012) 4621-4634. https://doi.org/10.1172/JCl62973. 
58. D. Pellacani, R.J. Packer, F.M. Frame, E.E. Oldridge, P.A. Berry, M.C. Labarthe, M.J. Stower, M.S. Simms, A.T. Collins, N.J. Maitland, Promoter hypermethylation, in: Epigenetics, Environ. Genes, Apple Academic Press, 2013: pp. 43-72. https://doi.org/10.1201/b14910.

59. K. Bin Cho, M.K. Cho, W.Y. Lee, K.W. Kang, Overexpression of c-myc induces epithelial mesenchymal transition in mammary epithelial cells, Cancer Lett. 293 (2010) 230-239. https://doi.org/10.1016/j.canlet.2010.01.013.

60. X. Gao, X. Liu, Y. Lu, Y. Wang, W. Cao, X. Liu, H. Hu, H. Wang, PIM1 is responsible for IL-6-induced breast cancer cell EMT and stemness via c-myc activation, Breast Cancer. (2019). https://doi.org/10.1007/s12282-019-00966-3.

61. S. Yin, V.T. Cheryan, L. Xu, A.K. Rishi, K.B. Reddy, Myc mediates cancer stem-like cells and EMT changes in triple negative breast cancers cells, PLoS One. 12 (2017). https://doi.org/10.1371/journal.pone.0183578.

62. H.T. Chen, H. Liu, M.J. Mao, Y. Tan, X.Q. Mo, X.J. Meng, M.T. Cao, C.Y. Zhong, Y. Liu, H. Shan, G.M. Jiang, Crosstalk between autophagy and epithelial-mesenchymal transition and its application in cancer therapy, Mol. Cancer. 18 (2019). https://doi.org/10.1186/s12943-019-1030-2.

63. M. Gugnoni, V. Sancisi, G. Manzotti, G. Gandolfi, A. Ciarrocchi, Autophagy and epithelialmesenchymal transition: An intricate interplay in cancer, Cell Death Dis. 7 (2016). https://doi.org/10.1038/cddis.2016.415.

64. B. Colella, F. Faienza, S. Di Bartolomeo, EMT regulation by autophagy: A new perspective in glioblastoma biology, Cancers (Basel). 11 (2019). https://doi.org/10.3390/cancers11030312.

65. R. Tan, L. Wang, J. Song, J. Li, T. He, Expression and significance of Twist, estrogen receptor, and Ecadherin in human breast cancer cells and tissues, J. Cancer Res. Ther. 13 (2017) 707. https://doi.org/10.4103/jcrt.JCRT_1396_16.

66. D. Grácio, F. Magro, R.T. Lima, V. Máximo, An overview on the role of autophagy in cancer therapy, Rev. Artic. Hematol. Med. Oncol. Hematol Med Oncol. 2 (2017) 1-4. https://doi.org/10.15761/HM0.1000117.

67. R.K. Amaravadi, C.B. Thompson, The roles of therapy-induced autophagy and necrosis in cancer treatment, Clin. Cancer Res. 13 (2007) 7271-7279. https://doi.org/10.1158/1078-0432.CCR-07-1595.

68. S. Fulda, Autophagy in cancer therapy, Front. Oncol. 7 (2017). https://doi.org/10.3389/fonc.2017.00128.

\section{Figures}



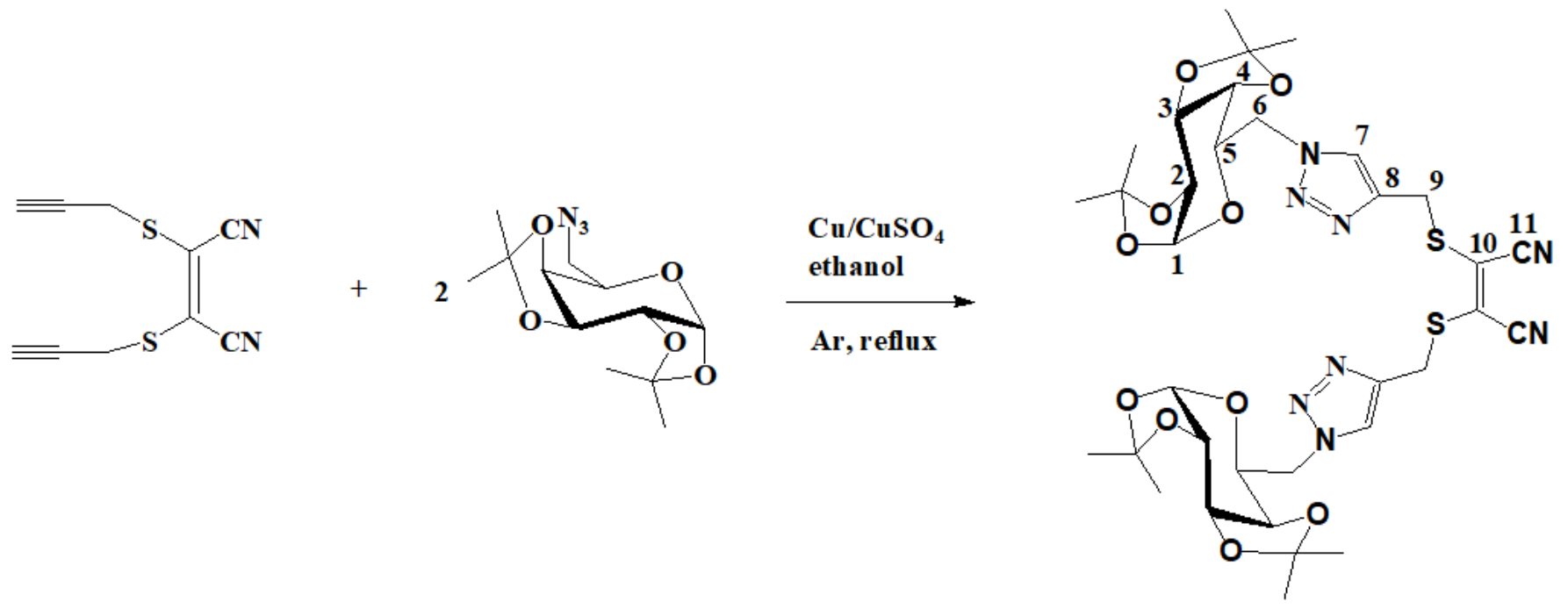

Figure 1

The synthesis stages of the DC and its chemical structure
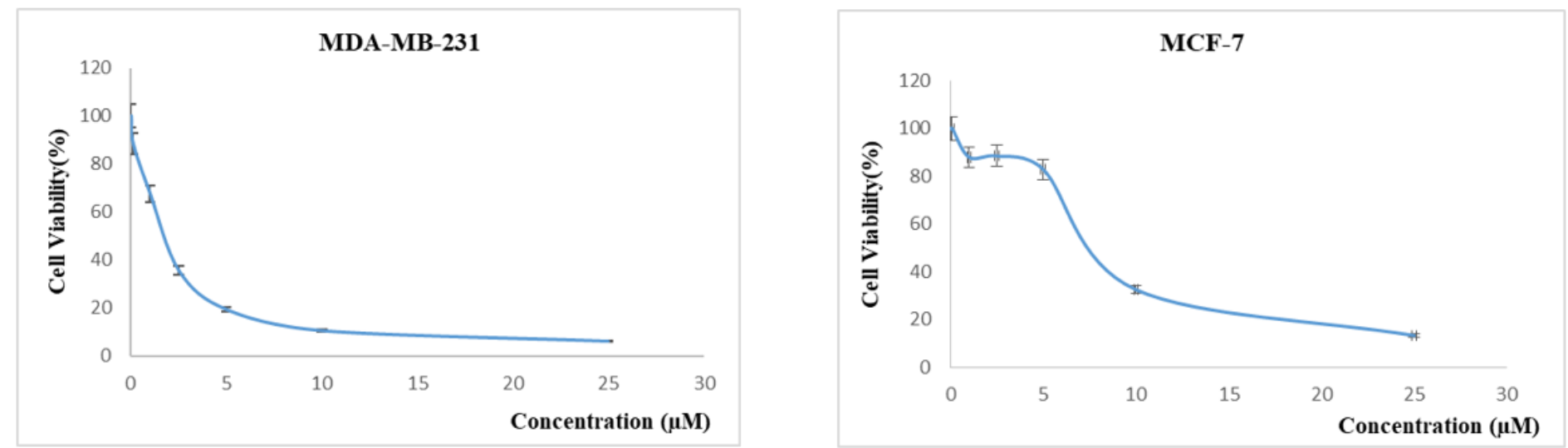

Figure 2

The DC has an anti-proliferative effect on breast cancer cell lines. The DC caused a significant decrease in cell viability of both cell lines as compared to untreated control samples as a dose-dependent manner. a: Proliferation graph of treated MDA-MB-231 cell line. b: Proliferation graph of treated MCF-7 cell line. (The graphs show the means \pm S.D. of a representative experiment performed in independent triplicate.) 
a.
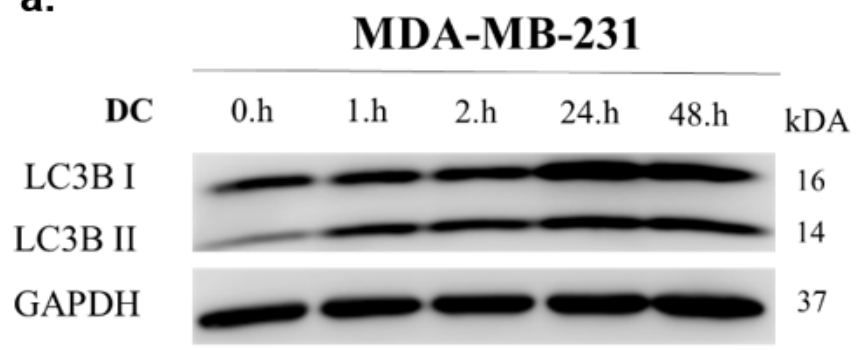

C.

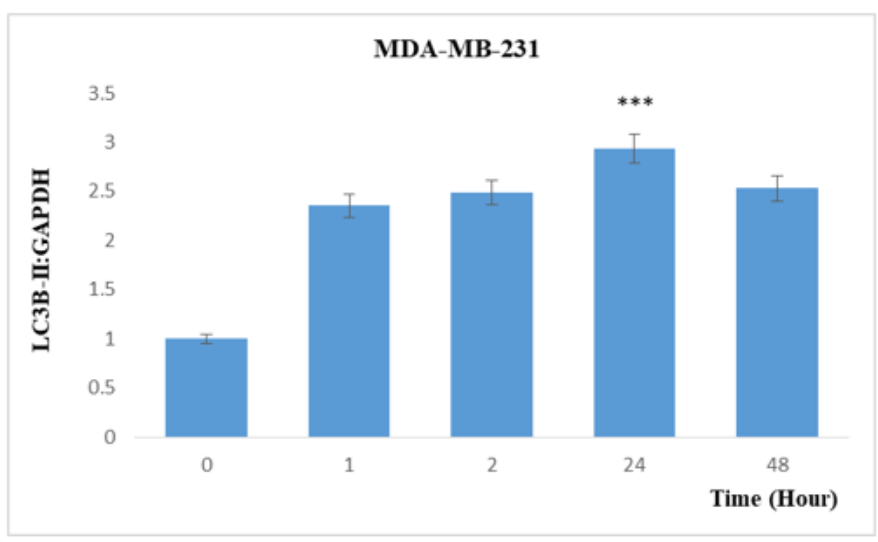

b.

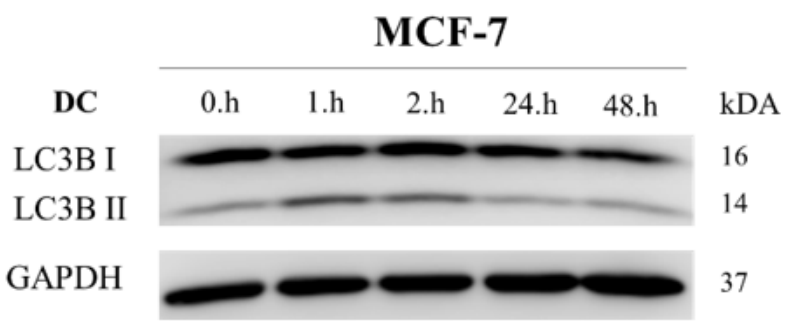

d.

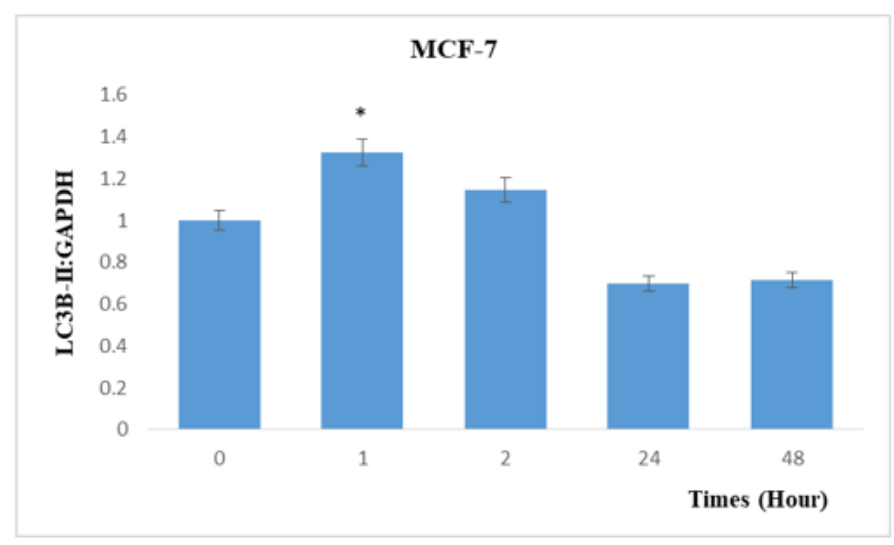

\section{Figure 3}

The DC induced autophagy in metastatic MDA-MB-231, but not in non-metastatic MCF-7 as long-term manner. $a, b)$ Protein expression of LC3B of 48-hour the DC-treated MDA-MB-231 and MCF-7 cell lines, respectively. (DC: the dicyano compound) $c, d$ ) The graphs depicting quantification of LC3BII:GAPDH ratios in the experimental set-up shown in a and b, respectively. ${ }^{*} p<0.05,{ }^{* \star} p<0.03,{ }^{\star \star *} p<0.01$ in comparison with the untreated group. The graphs show the means \pm S.D. of a representative experiment performed in independent triplicate.) 
a.

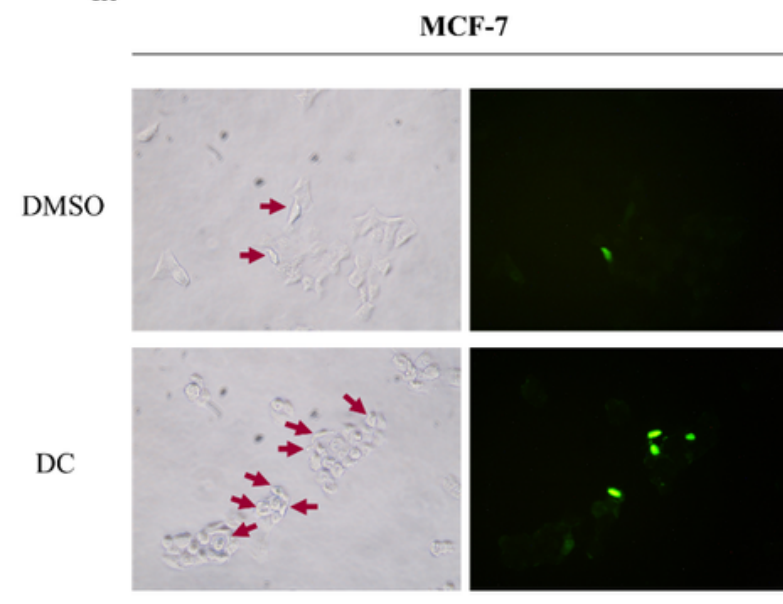

b.
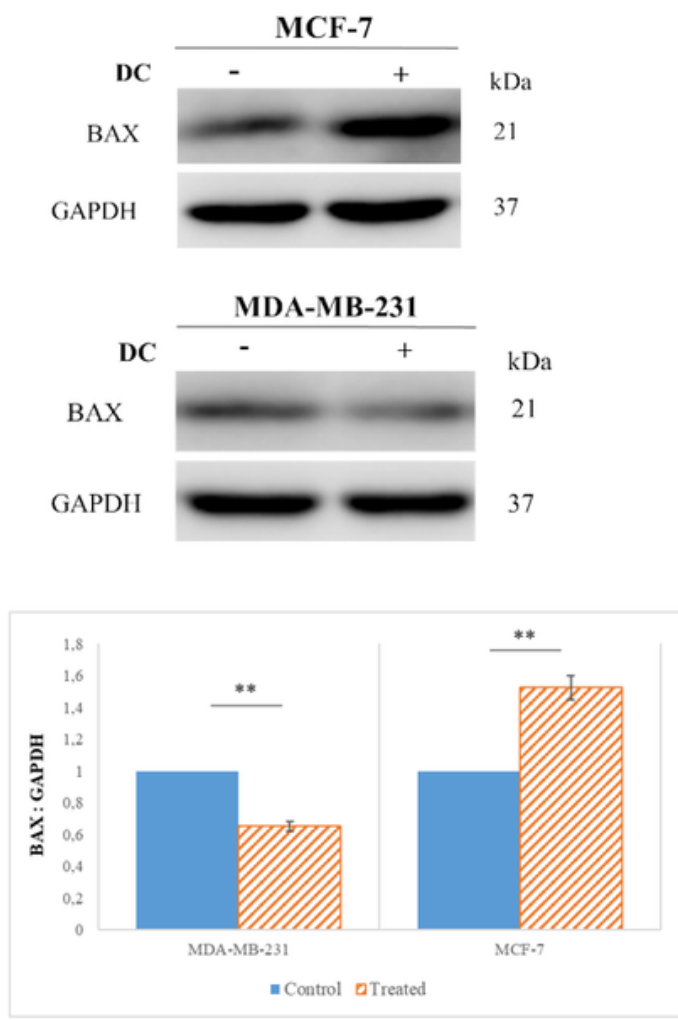

MDA-MB-231

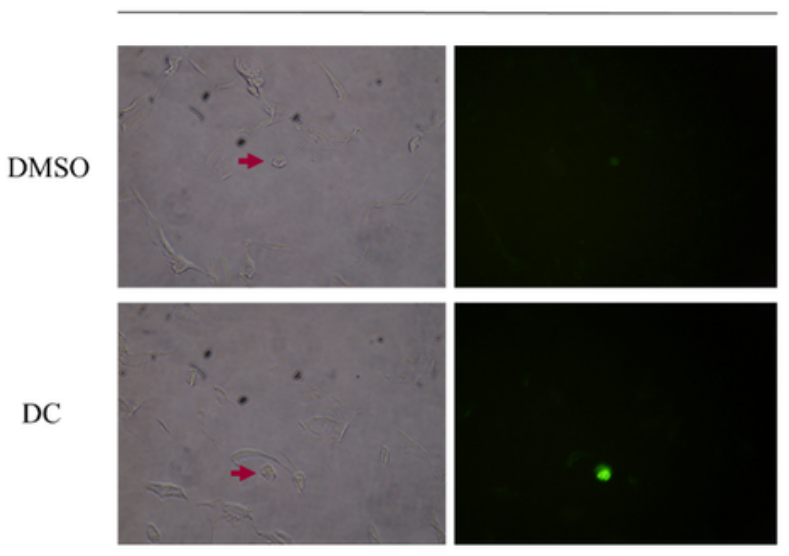

c.
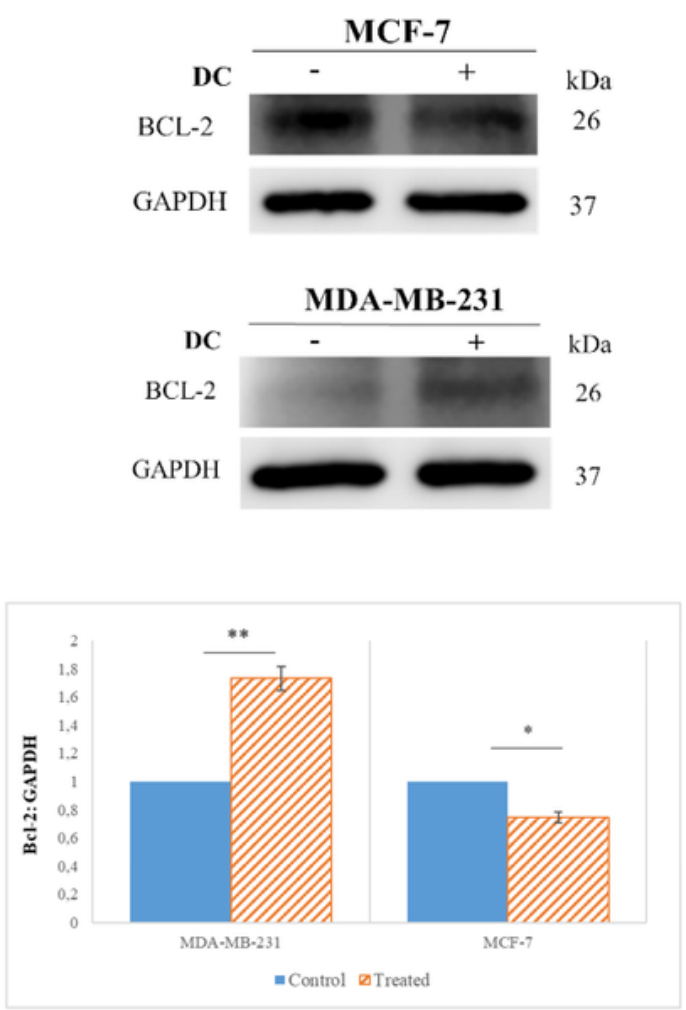

\section{Figure 4}

The DC induced apoptosis in non-metastatic MCF-7, not in metastatic MDA-MB-231 cell lines.

Determination of apoptosis in 48-hour the DC-treated MCF-7 and MDA-MB-231 cell lines by TUNEL a) Brightness and $480 \mathrm{~nm}$ wavelength phase image of control group and the DC-treated group of MCF-7 and MDA-MB-231 cell lines, respectively. b, c) Immunoblots of pro-apoptotic BAX and anti-apoptotic Bcl-2 in 48-hour DC-treated MCF-7 and MDA-MB-231 cell line and the graphs depicting quantification of the 
protein levels. (DC: the dicyano compound) $\left({ }^{*} p<0.05,{ }^{* \star} p<0.03,{ }^{* \star *} p<0.01\right.$ in comparison with the untreated group. The graphs show the means \pm S.D. of a representative experiment performed in independent triplicate.)
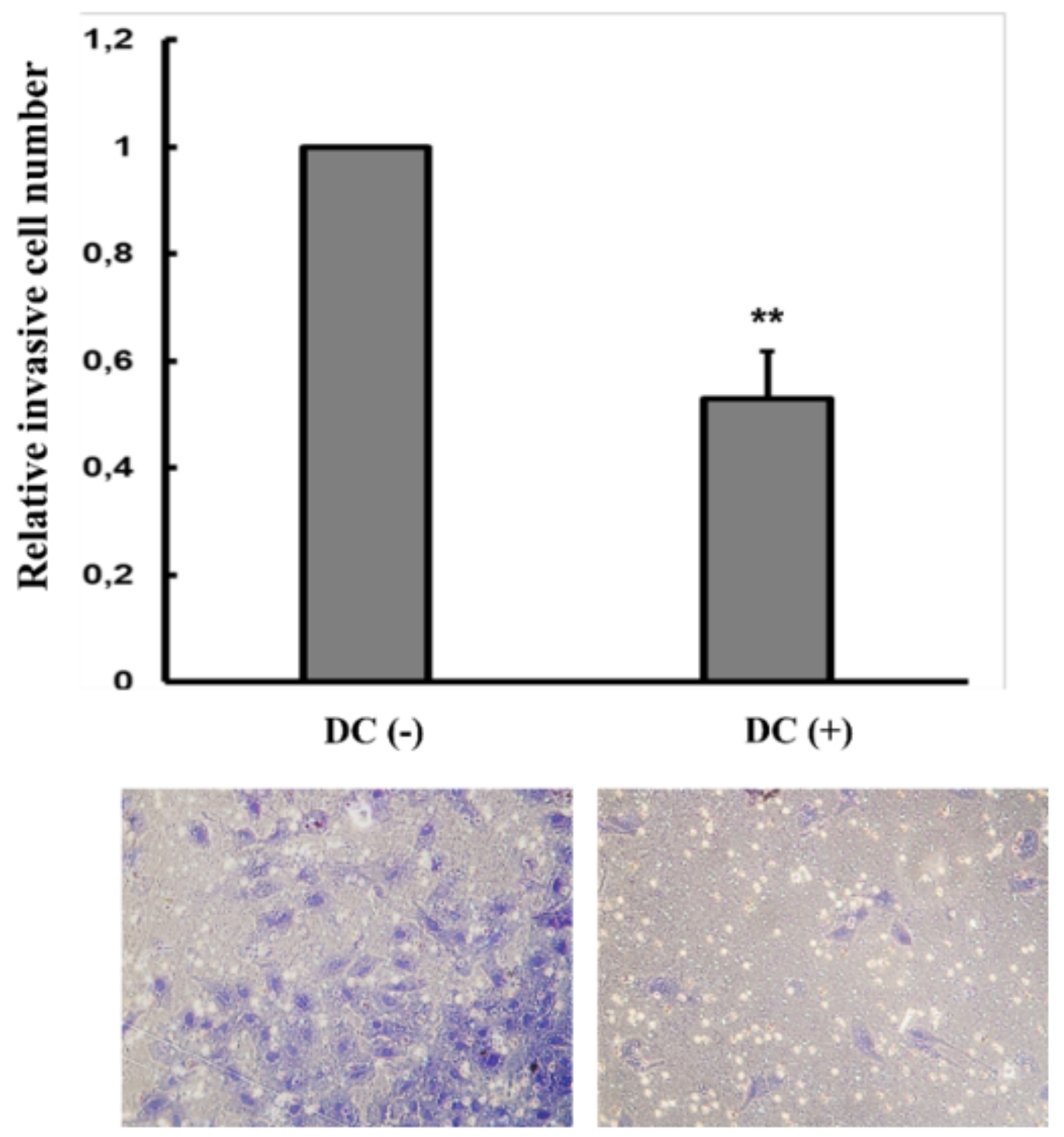

\section{Figure 5}

The DC reduces invasive capability of metastatic MDA-MB-231 cell line. Invasion capability of MDA-MB231 cells untreated and treated with the DC during 48 hours, respectively $\left({ }^{\star} p<0.05,{ }^{* \star} p<0.03,{ }^{* \star *} p<0.01\right.$ in comparison with the untreated group. The graphs show the means $\pm S$.D. of a representative experiment performed in independent triplicate.) 
a.

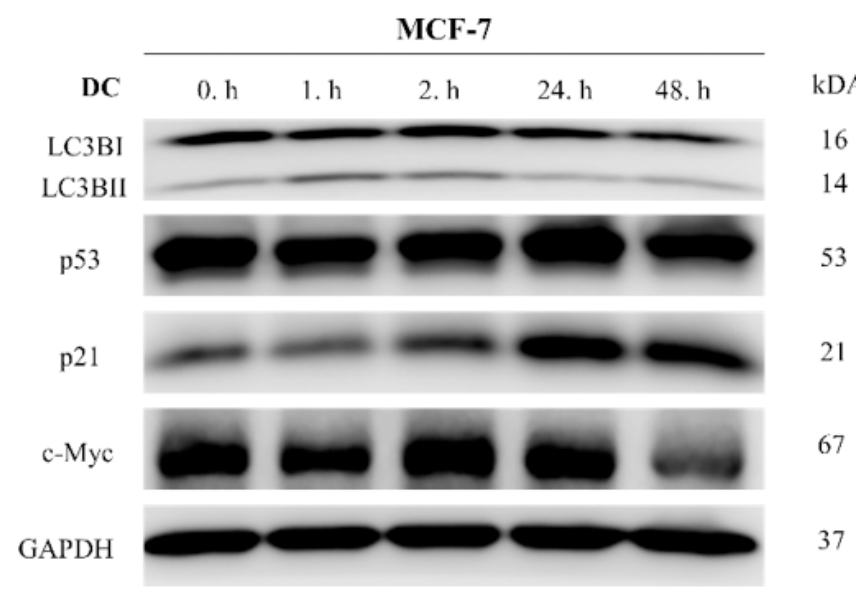

c.

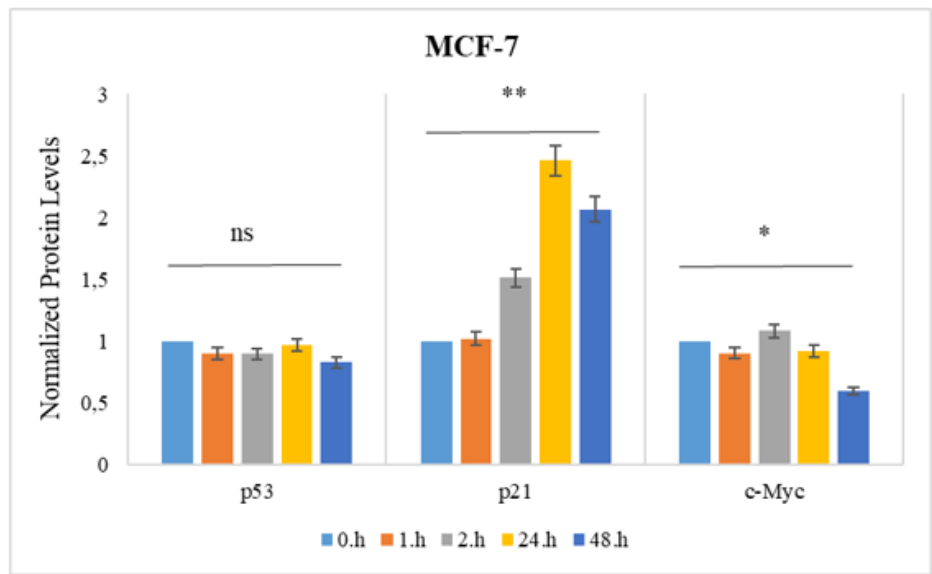

b.

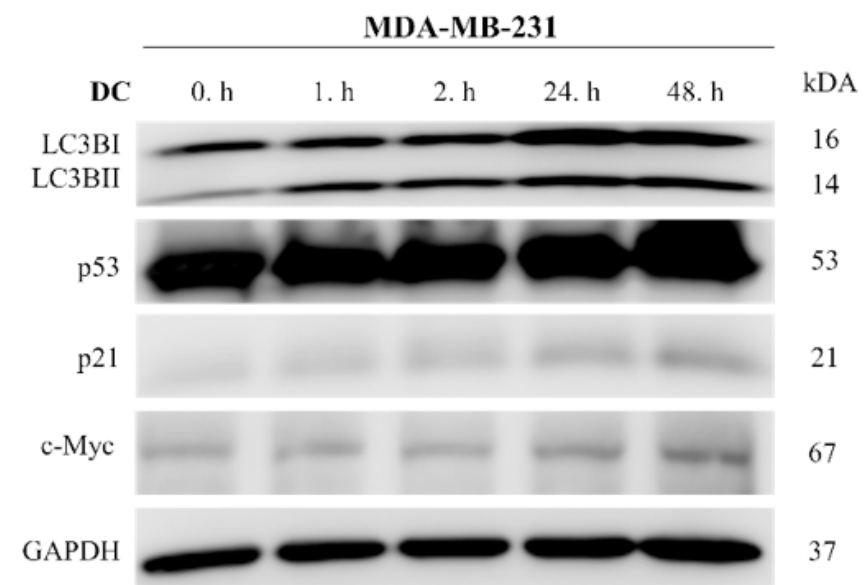

d.

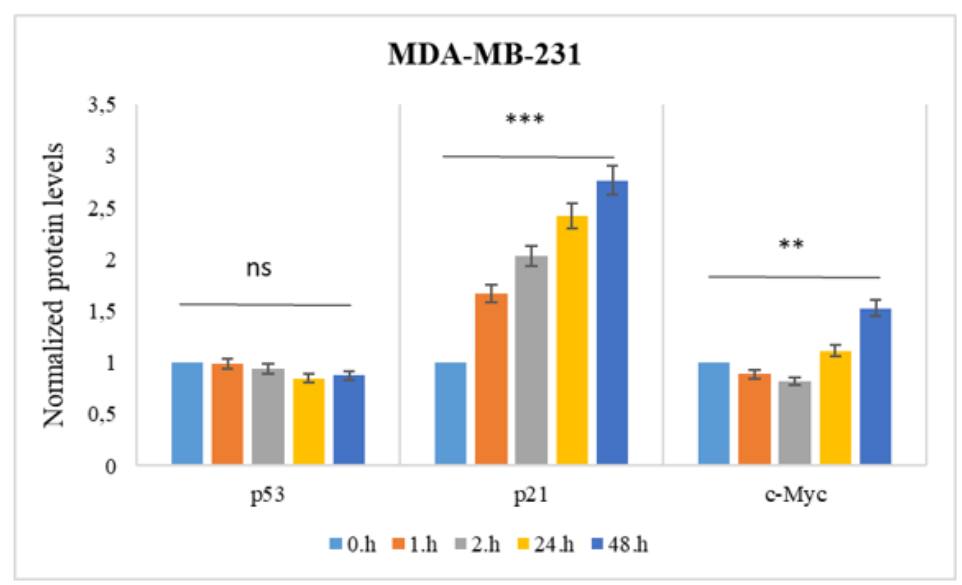

\section{Figure 6}

The DC regulated c-Myc and p21 expression levels as a p53-independent manner. a, b) Immunblots of p53, p21 and c-Myc protein in MCF-7 and MDA-MB-231 cell lines, respectively. c, d) The bar graphs represent normalized expression levels of respective proteins in the experimental set-up shown in $a$ and $b$, respectively. ( ${ }^{*} p<0.05,{ }^{*} p<0.03,{ }^{* \star} p<0.01$ in comparison with the untreated group. The graphs show the means \pm S.D. of a representative experiment performed in independent triplicate.) 
a.

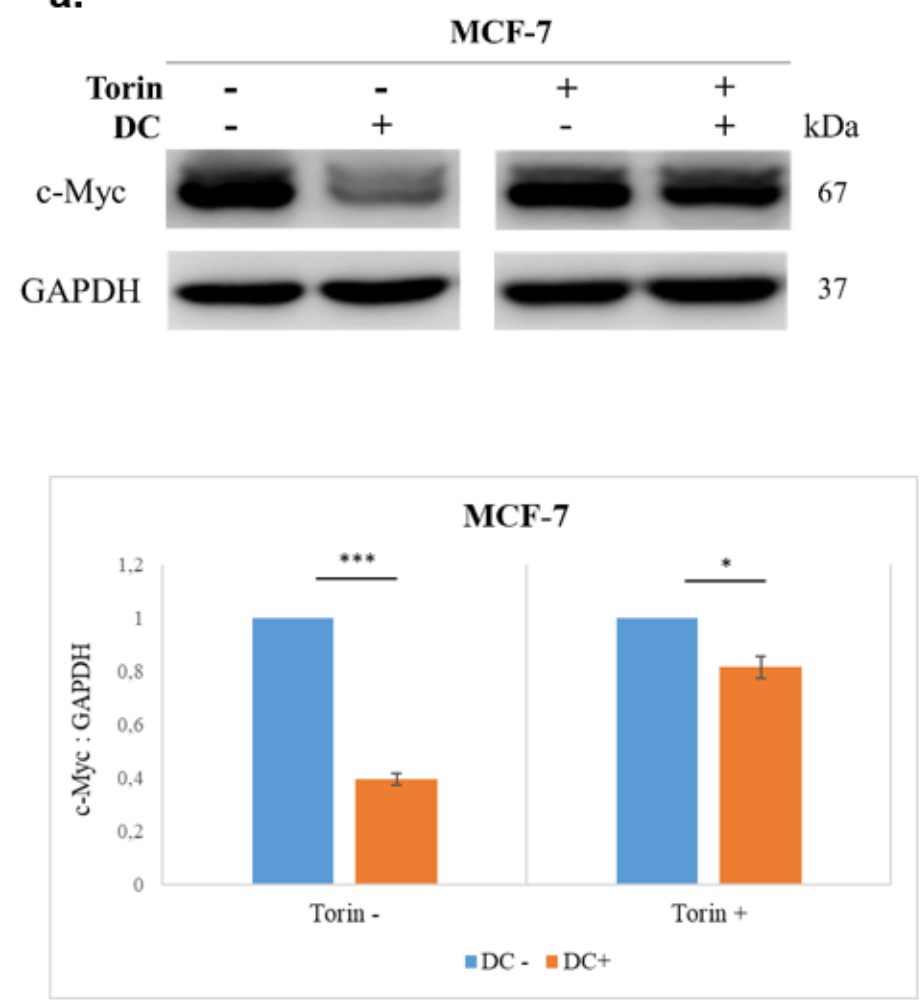

b.

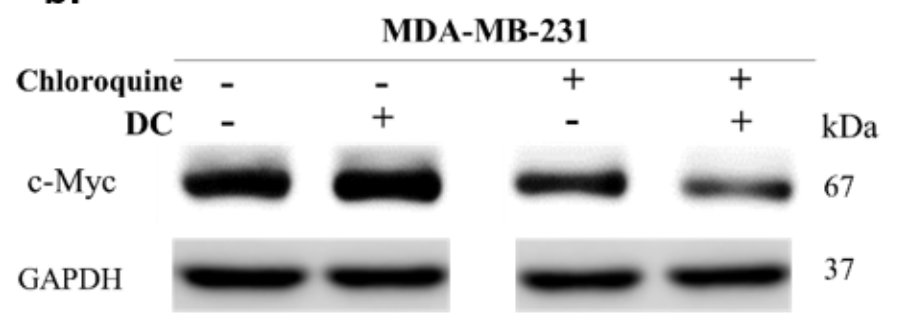

\section{Figure 7}

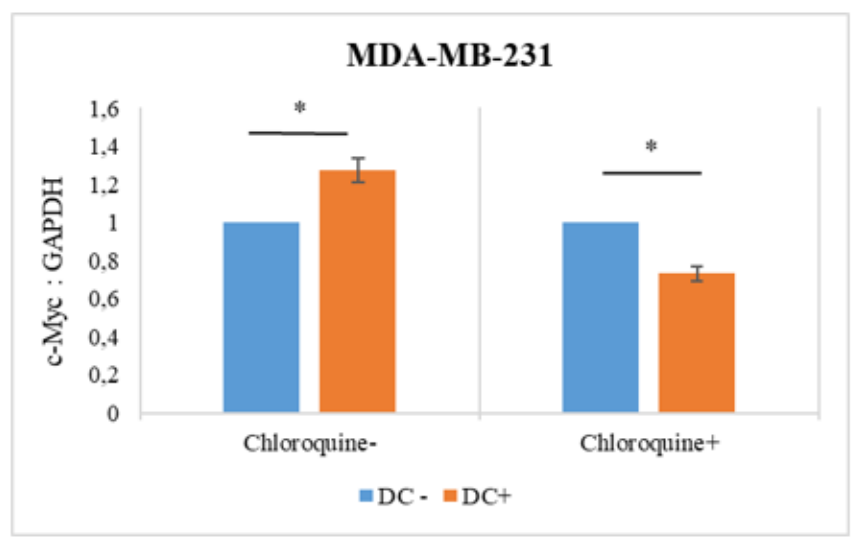

C-Myc may play role in selection of cell death pathway following the DC. Immunblots of c-Myc protein in MCF-7 cell line in which is autophagy was induced by Torin (a) and in MDA-MB-231 cell line in which is autophagy was blocked by chloroquine (b) The bar graphs represent quantification of c-Myc:GAPDH ratios in the experimental set-up shown in a and $b$, respectively $\left({ }^{*} p<0.05,{ }^{*} p<0.03,{ }^{* * *} p<0.01\right.$ in comparison with the untreated group. The graphs show the means \pm S.D. of a representative experiment performed in independent triplicate.) 
a.

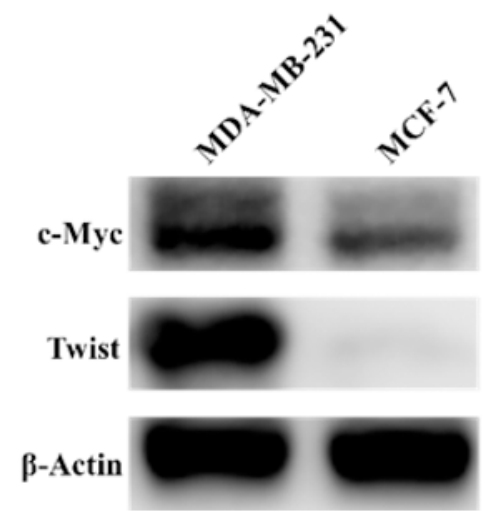

b.

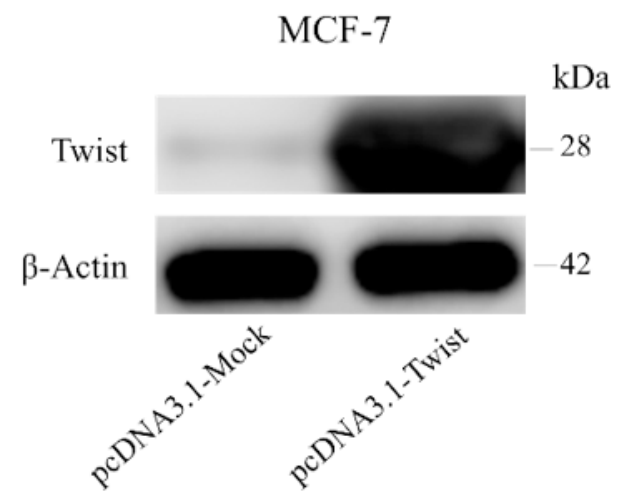

c.
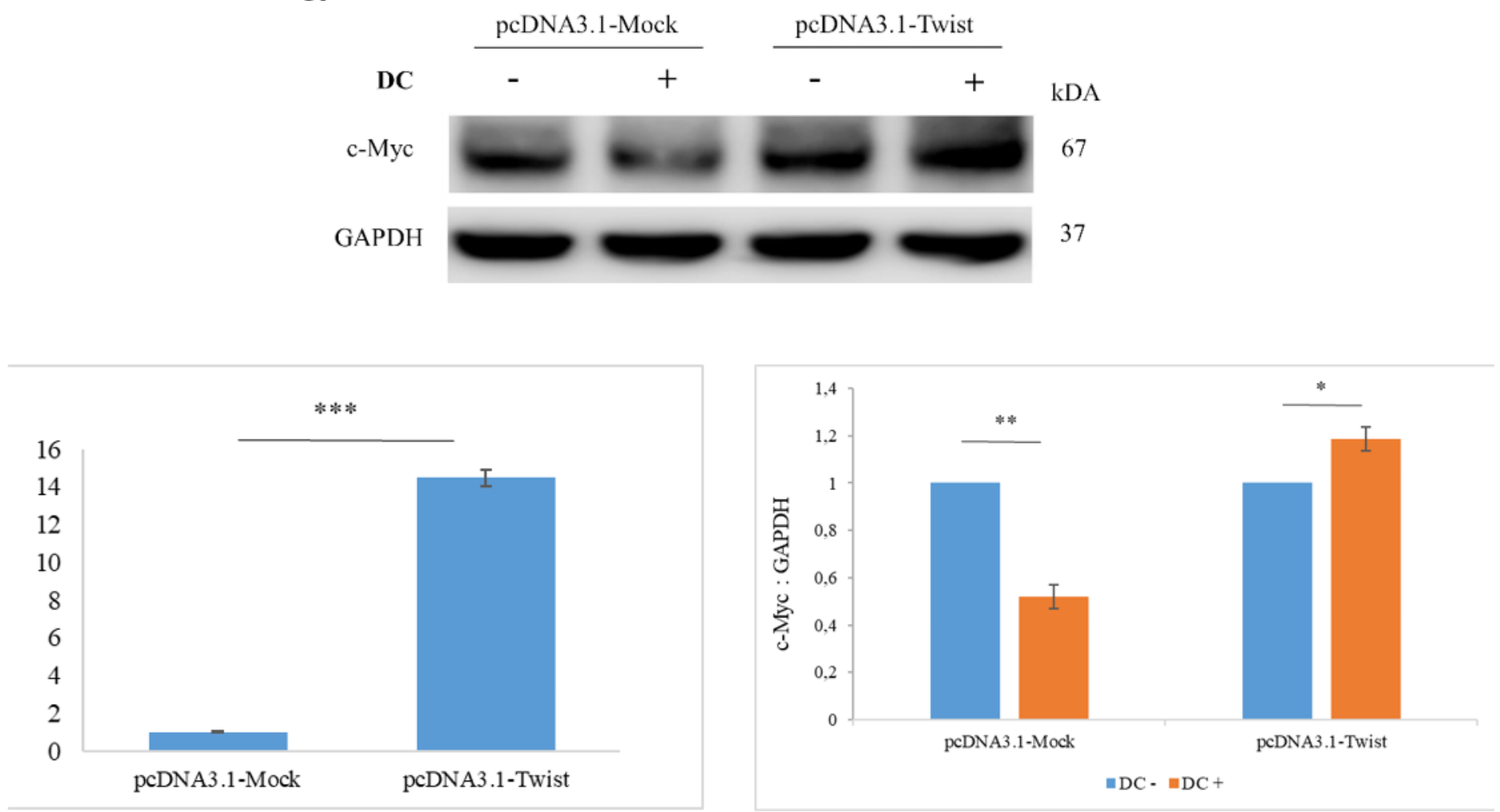

\section{Figure 8}

Twist abolished the DC-induced c-Myc downregulation in MCF-7 cell line. (a) Immunblots of c-Myc and Twist proteins in MDA-MB-231 and MCF-7 untreated cell lines (b) Immunblots of c-Myc protein in MCF-7 cell line which was transfected by pcDNA3.1-Mock and pcDNA3.1-Twist plasmids (c) The bar graphs represent normalized expression levels of Twist and c-Myc in the experimental set-up shown in b and c, respectively. (The graphs show the means \pm S.D. of a representative experiment performed in independent triplicates.) 

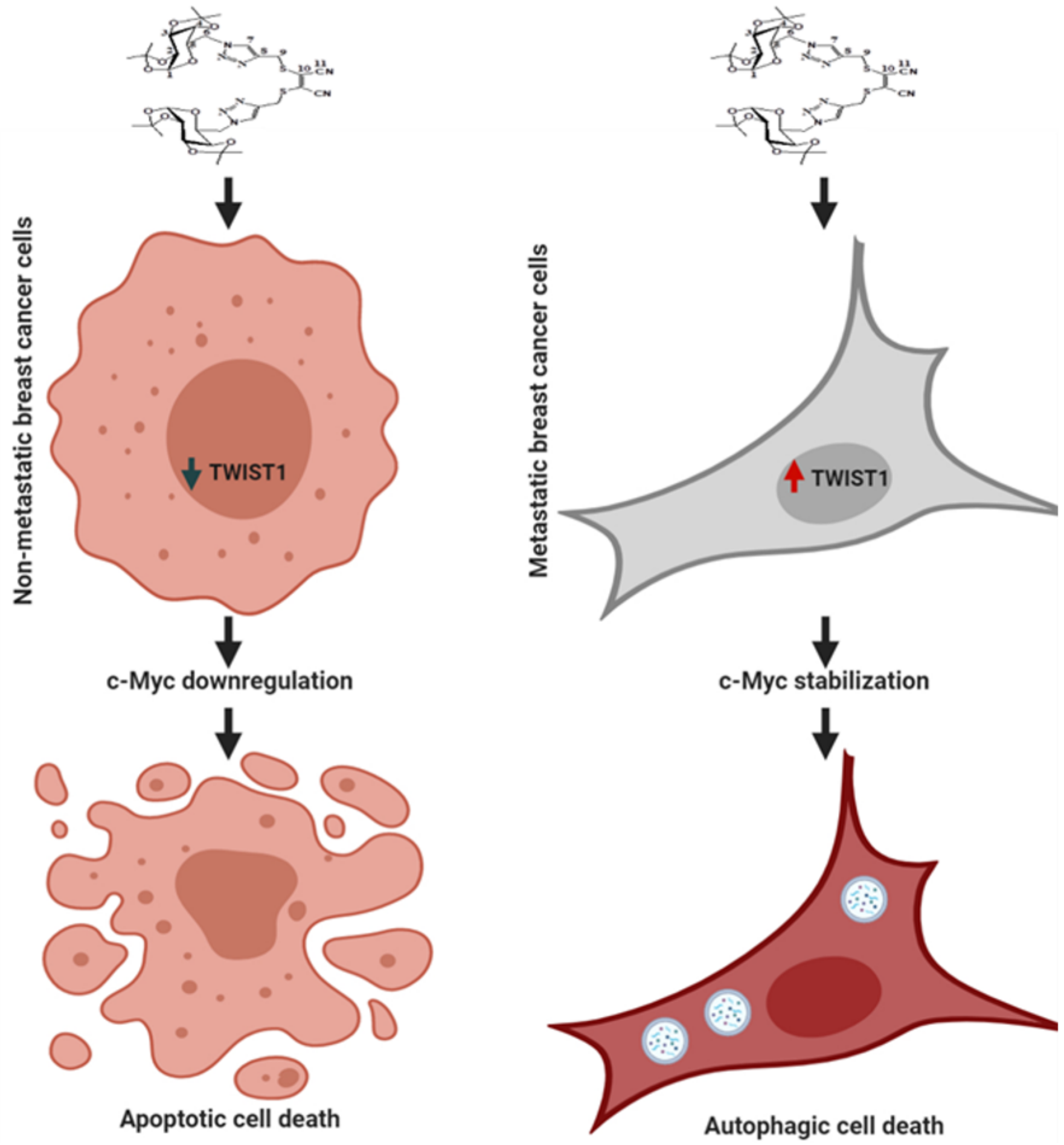

Figure 9

The schematic representation of the results. 